\title{
Calreticulin mediates an invasive breast cancer phenotype through the transcriptional dysregulation of p53 and MAPK pathways
}

\author{
Mohammadreza Zamanian 1,2, Lama Abdel Qader Hamadneh33, Abhi Veerakumarasivam², \\ Sabariah Abdul Rahman ${ }^{5}$, Shamarina Shohaimi ${ }^{6}$ and Rozita Rosli, ${ }^{2,7^{*}}$
}

\begin{abstract}
Background: The introduction of effective novel biomarkers of invasion and metastasis is integral for the advancement of breast cancer management. The present study focused on the identification and evaluation of calreticulin (CRT) as a potential biomarker for breast cancer invasion.

Methods: Two-dimensional gel protein electrophoresis and MALDI-TOF were utilized in the analysis of fresh-frozen invasive intra-ductal carcinoma specimens. Calreticulin-associated expression was analyzed using immunohistochemistry of FFPE non-malignant/malignant breast specimens. A CRT-knockdown model of MCF7 cell line was developed using siRNA and the CRT genotype/phenotype correlations based on migration and trans-well invasion assays were determined. Finally, microarray-based global gene expression profiling was conducted to elucidate the possible calreticulin pro-invasive regulatory pathways.

Results: Two-dimensional gel protein electrophoresis and MALDI-TOF analysis showed upregulation of calreticulin expression in tumor tissues as compared to the normal adjacent tissues. Meta-analysis of the immunohistochemical results confirmed significantly higher expression of calreticulin $(p<0.05)$ in the stromal compartments of malignant tissues as compared to non-malignant tissues. Migration and transwell invasion assays showed significant loss in the migratory and invasive potential of $C R T$-knockdown cells $(p<0.05)$. Global gene expression profiling successfully identified various putative gene networks such as p53 and MAPK pathways that are involved in calreticulin breast cancer signaling.
\end{abstract}

Conclusion: Besides confirming calreticulin overexpression in invasive breast cancer tissues, this study reveals a calreticulin-dependent pro-invasive potential and suggests possible contributing pathways. Defining the mechanistic role of invasion and characterizing the possible calreticulin-dependent molecular targets will be the focus of future work.

Keywords: Calreticulin, Breast cancer, Invasion, p53, MAPK

\section{Background}

Breast cancer is a major health problem for women as it is diagnosed at least a million times every year worldwide [1]. In the United States, it is the second leading cause of cancer deaths and the most common cancer

\footnotetext{
*Correspondence: rozita@upm.edu.my

7 UPM-MAKNA Cancer Research Laboratory, Institute of Bioscience,

Universiti Putra Malaysia, 43400 Serdang, Selangor, Malaysia

Full list of author information is available at the end of the article
}

among women [2]. In Asian countries, the peak age for the disease is between 40 and 50 with an increasing trend in incidence and associated mortality [3]. The ability to accurately predict the presence of distant metastasis; the direct consequence of the invasive ability of cancer cells significantly aids in the determination of effective patient management strategies [4].

Calreticulin (CRT) is an important endoplasmic reticulum (ER) protein with critical functions inside and outside the ER [5]. Protein chaperoning and calcium 
homeostasis are the two key functions of calreticulin inside the lumen of the ER [6]. Outside the ER, calreticulin is involved in cell adhesion [7], modification of gene expression [8], and immune response [9]. Calreticulin is also reported to be correlated with cellular proliferation and metaplastic events [8]. In addition, calreticulin has also been linked to malignant states [10], and as a major calcium homeostasis contributor, it plays a role in cancer invasion and metastasis [11]. Recent studies have focused on revealing an association between the presence of calreticulin and the initiation or progression of various malignant transformations [12]. In brief, the tumorpromoting effects of calreticulin or its overexpression has been reported in ductal carcinoma of the breast [13], bladder cancer [14], and prostatic adenocarcinoma [15]. Furthermore, hepatocellular carcinoma [16], pancreatic malignancies [17], esophageal cancer [18], gastric cancer [19], colon cancer [20], melanoma [21], and leukemia [22] have also been reported to be potentially correlated with calreticulin activity.

A higher expression of calreticulin protein in breast ductal adenocarcinomas has been previously reported [13], which possibly indicates to a correlation between the presence of calreticulin and the initiation and/or progression of cancer. Calreticulin overexpression was also found to be associated with a higher risk of developing invasion and metastasis in breast cancer patients [23]. In addition, calreticulin has been suggested to be a potential biomarker for breast cancer prognosis as its expression was associated with more advanced tumors [24].

Taken together, calreticulin is believed to be involved in the initiation and progression of various cancers. In breast cancer, calreticulin expression has been correlated with more advanced disease and a higher chance for the development of distant metastasis. As the mechanisms and the pathways through which calreticulin may contribute to breast cancer invasion and metastasis have not been determined, we first tried to clarify the importance of calreticulin stromal expression in conferring a more invasive phenotype to breast cancer and to subsequently propose possible mechanisms or pathways for calreticulin pro-invasive effects. The proteomic component of the present study revealed calreticulin as differentially expressed in various invasive states of breast cancer. Then we focused on evaluating the possible correlations between calreticulin expression and the conferment of an invasive phenotype in breast cancer cells as well as clarifying the related mechanisms. We aimed to probe the patterns of differential expression of calreticulin in a range of human breast tissues including non-malignant and malignant lesions. Subsequently, we established the role of $C R T$ in conferring an invasive phenotype in breast cancer cells through siRNA gene knockdown and whole genome expression profiling.

\section{Results}

Two-dimensional gel electrophoresis protein maps in the range of $\mathrm{pH} 4-7$ were obtained in duplicates and protein spots that were differentially expressed between tumor and adjacent normal epithelial tissues were selected. Figure 1a shows a representative gel where the protein spots are circled. Spots that were differentially expressed across different samples were excised and sent for MALDI-TOF analysis. Figure $1 \mathrm{~b}$ represents the MALDITOF spectrogram for calreticulin tryptic peptides while all of the correlated identified spots are also listed in Additional file 1: Table S1. The results revealed that calreticulin is overexpressed in the tumoral regions of the tissue samples (spot 2 in Fig. 1a). Figure 1c represents calreticulin expression in different intra ductal carcinoma (IDC) samples including the tumoral and normal adjacent tissues. By using qPCR, CRT expression was confirmed to be higher in stages III and IV of breast cancer as compared to stage I and II tumors (Fig. 1d). Results from protein profiling revealed differential calreticulin expression patterns between tumoral and normal adjacent tissues of breast cancer specimens.

To confirm our protein profiling results and characterize the histological pattern of calreticulin expression, we applied IHC on a range of breast cancer specimens with varying degrees of invasive potential. Our results confirmed that in non-malignant tissues, calreticulin expression was more prominent in the glandular compartment as compared to the stroma (Fig. 2a). The expression was mostly cytoplasmic while low intense staining of the nucleus and cell membrane was also detectable. In malignant tissues, calreticulin was expressed in both the epithelial and stromal compartments (Fig. 2b). The expression was high in almost all malignant epithelial cells while inside the tumor stroma, high expression of calreticulin could be observed in spindle shaped cells of the stroma. The pattern of expression revealed that the higher the invasive state of the tissue, the more calreticulin was expressed. To quantify the differences in calreticulin expression among various malignant states, IHC results were scored and the different categories (non-malignant/malignant/stage/grade) were compared (Fig. 2c). One-way ANOVA followed by post hoc test (Duncan option) demonstrated a significantly higher expression of calreticulin in the stromal compartments of malignant tissues as compared to non-malignant tissues; as $\mathrm{F}(3,41)=4.985$ and $\mathrm{p}=0.005$ (Table 1 ).

Since IHC confirmed the differential expression of calreticulin in breast cancer tissues, we developed an in vitro $C R T$-knockdown model of breast cancer using 


\section{a}
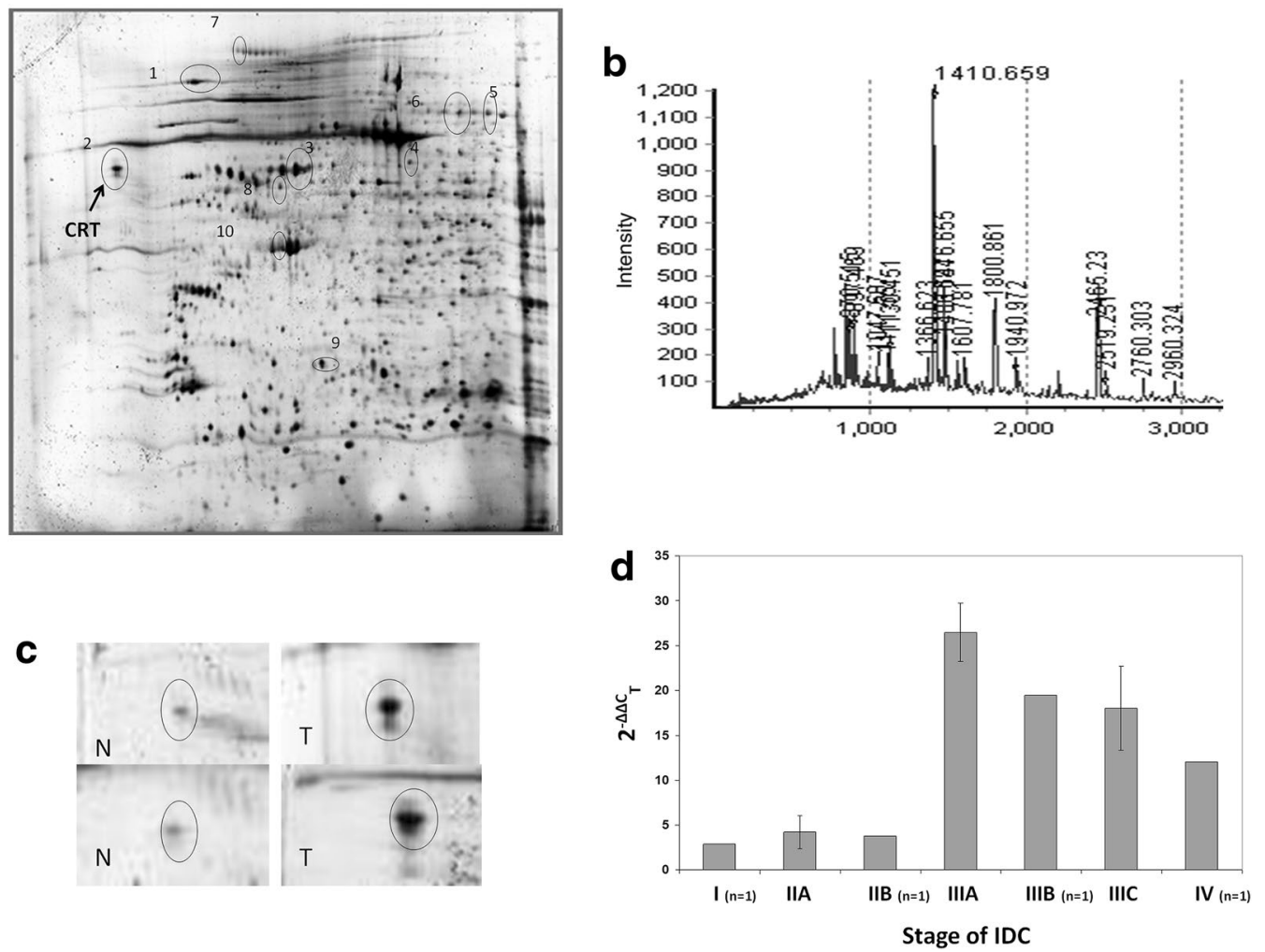

Fig. 1 Two-dimensional gel electrophoresis and MALDI-TOF mass spectra analysis reveal calreticulin as over expressed in breast cancer tissues. a A representative 2D gel electrophoresis map for the tumor tissue from a stage III sample after running on $17 \mathrm{~cm} \mathrm{pH} \mathrm{4-7} \mathrm{IPG} \mathrm{strips.} \mathrm{Spots} 1$ through 9 were excised and the protein identification was determined by MALDI-TOF analysis, in which spots 1-5 and spot 9 were over-expressed in the tumor tissue, while spots 6-8 were down-regulated. b MALDI-TOF mass spectrum of the tryptic peptides corresponding to calreticulin. c Expression of calreticulin in different intra ductal carcinoma (IDC) samples ( $T$ tumoral tissue, $N$ normal adjacent tissue). d Graph represents the CRT expression fold change across different stages of infiltrating ductal breast carcinoma specimens

siRNA to examine the effects of CRT expression modulation on the invasive potential of MCF7 breast cancer cells. The level of CRT expression decreased by $87 \%$ following siRNA transfection (Additional file 2: Table S2; Fig. 3a), which confirmed the successful knockdown of $C R T$. This was further confirmed by western blot analysis (Fig. 3b). In addition, MTT assay was used to evaluate the presence of potential cytotoxic effects of the siRNA and transfection reagent. The mean viability of the CRTknockdown cells remained at about $90 \%$ as compared to untreated cells (Fig. 3c).

The invasive characteristics of $C R T$-knockdown cells were then investigated using phenotypic assays. The migration assay (Additional file 3: Table S3; Figs. 3d, 4) revealed a significant decrease in the migratory potential of CRT-knockdown cells as compared to the control group $(\mathrm{p}<0.05)$. The treatment with mitomycin- $\mathrm{C}$ did not alter this effect, suggesting that the inhibitory effect of calreticulin on migration is not proliferation-dependent $(\mathrm{p}<0.05)$.
The mean number of invaded CRT-knockdown cells in a matrigel invasion assay (Additional file 4: Table S4; Fig. 5) was compared against the controls (Fig. 3e). There was a significant decrease $(\mathrm{p}<0.05)$ in the number of invaded CRT-knockdown cells as compared to the control cells.

We then tried to identify possible $C R T$-associated signaling pathways using gene expression microarrays. A total of 1579 genes were significantly upregulated while 992 genes were downregulated in the CRT-knockdown cells. The 10 most up/downregulated genes are summarized in Table 2. The validity of the microarray data was confirmed using qPCR (Fig. 6).

To understand the biological significance of the global changes in the patterns of gene expression, related gene ontologies were analyzed. GeneCards ${ }^{\circledR}$ which is one of the options of GeneDecks V3 software was used for annotation classification. DAVID (Database for Annotation, Visualization and Integrated Discovery) was also used to reveal functional relationships of the proposed 


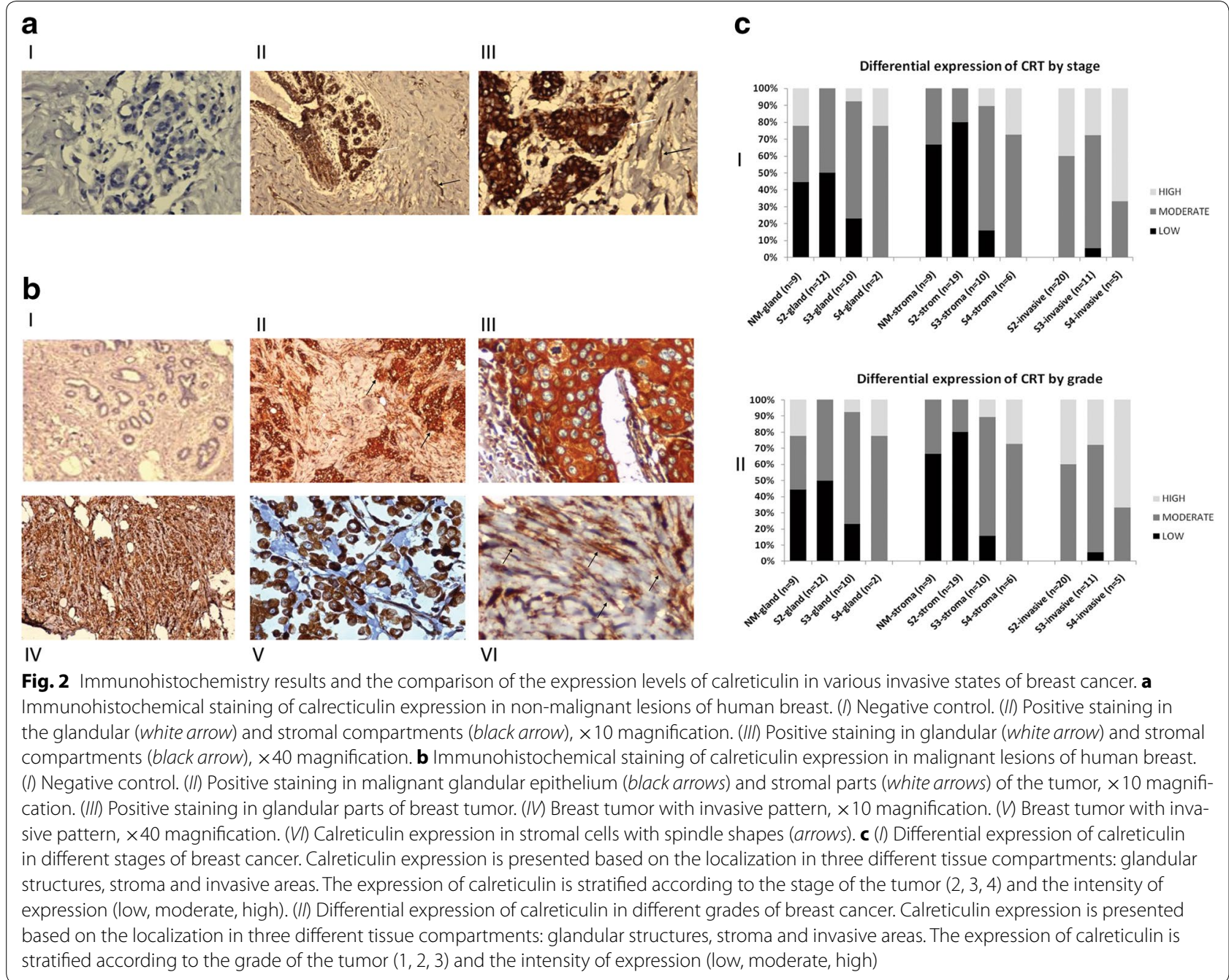

subsets of genes and related ontologies. Some of the most important and related ontologies for up/down-regulated genes are summarized in Additional file 5: Table S5. The genes in each category have been previously reported in the literature as responsible for or involved in the specific ontologies.

Among the significantly upregulated genes, $M I A$ (melanoma inhibitory activity), KLK13 (kallikrein-related peptidase 13), HEPACAM (hepatic and glial cell adhesion molecule), $M A D D$ (MAP-kinase activating death domain), TP53I11 (tumor protein p53 inducible protein 11 ), based on the importance of their cellular localization have been reported as being associated with a more invasive cancer phenotype. In addition, LGALS3BP (lectin, galactoside-binding, soluble, 3 binding protein), MAP3K5 (mitogen-activated protein kinase kinase kinase 5), TNFSF10 (tumor necrosis factor (ligand) superfamily, member 10) which are mainly involved in various cellular processes are potentially associated with a higher invasive potential. Finally, BTG2 (BTG family, member 2), RARRES3 (retinoic acid receptor responder 3), SERPINA3 (serpin peptidase inhibitor, clade A (alpha-1 antiproteinase, antitrypsin), member 3), SMPD3 (sphingomyelin phosphodiesterase 3 , neutral), XAF1 (XIAP associated factor 1), SERPINB5 (serpin peptidase inhibitor, clade B (ovalbumin), member 5) and TP53TG5 are important cancer-related genes that were also significantly up-regulated in this study.

Among the significant downregulated genes, CCT5 (chaperonin containing TCP1, subunit 5), DBF4, HDAC4 (histone deacetylase 4), HDAC4 and TAF3 with important cellular localizations were shown to be correlated with higher invasive potential. In addition, CALB2 (calbindin 2) or calretinin, MAPRE2 (microtubule-associated protein, RP/EB family, member 2), RNASE1 (ribonuclease, RNase A family, 1), ESRRG or estrogen related receptor gamma, MAPK8 (mitogen-activated protein kinase 8 ) and PCMT1 (protein-L-isoaspartate (D-aspartate) 
Table 1 Statistical analysis of immunohistochemistry results for calreticulin expression (ANOVA)

\begin{tabular}{|c|c|c|c|c|c|}
\hline Stage & Sum of squares & df & Mean square & $\mathbf{F}$ & Sig. \\
\hline \multicolumn{6}{|l|}{ Glandular tissue } \\
\hline $\begin{array}{l}\text { Between } \\
\text { groups }\end{array}$ & 10.854 & 3 & 3.618 & 0.777 & 0.516 \\
\hline Within groups & 139.617 & 30 & 4.654 & & \\
\hline Total & 150.471 & 33 & & & \\
\hline \multicolumn{6}{|l|}{ Stroma } \\
\hline $\begin{array}{l}\text { Between } \\
\text { groups }\end{array}$ & 60.128 & 3 & 20.043 & 4.985 & 0.005 \\
\hline Within groups & 164.85 & 41 & 4.021 & & \\
\hline Total & 224.978 & 44 & & & \\
\hline \multicolumn{6}{|c|}{ Invasive carcinoma } \\
\hline $\begin{array}{l}\text { Between } \\
\text { groups }\end{array}$ & 28.301 & 2 & 14.15 & 3.213 & 0.053 \\
\hline Within groups & 145.338 & 33 & 4.404 & & \\
\hline Total & 173.639 & 35 & & & \\
\hline
\end{tabular}

One-way ANOVA showed significantly higher calreticulin expression in stromal parts of malignant tissues as compared to non-malignant samples $(p<0.05)$

O-methyltransferase) which are involved in various cellular processes have been reported to be associated with a more invasive cancer phenotype. Finally, C11orf17 (A kinase interacting protein 1), MAP2K6 (mitogen-activated protein kinase kinase 6: MKK6), PARD6A (par-6 partitioning defective 6 homolog alpha), MINA (MYC induced nuclear antigen), NUDT6 (fibroblast growth factor 2: FGF-2), PSMD10 (proteasome (prosome, macropain) $26 \mathrm{~S}$ subunit, non-ATPase, 10: $p 28$ ), PSMD10, FABP3 (fatty acid binding protein 3), $A M P K$ (AMP-activated protein kinase) and PRND (prion protein 2) have been suggested to potentially contribute towards the migratory and morphological behavioral changes of tumor cells.

We also probed for any significant changes in the expression of other genes related to calreticulin chaperoning or calcium homeostasis. Our results showed significant overexpression of ERp57, GRP78 and GRP94 in $C R T$-knockdown breast cancer cells. These proteins are actively involved in protein chaperoning inside the ER. In addition, $E R O 1 A$ which codes for an oxidizing enzyme involved in the regulation of the redox state of various ER proteins showed significant upregulation in $C R T$-knockdown genes. Finally, ITPR3 which encodes the receptor for inositol 1,4,5-trisphosphate was downregulated in $C R T$-knockdown cells. ITPR3 contains a calcium channel and is involved in the release of intracellular calcium.
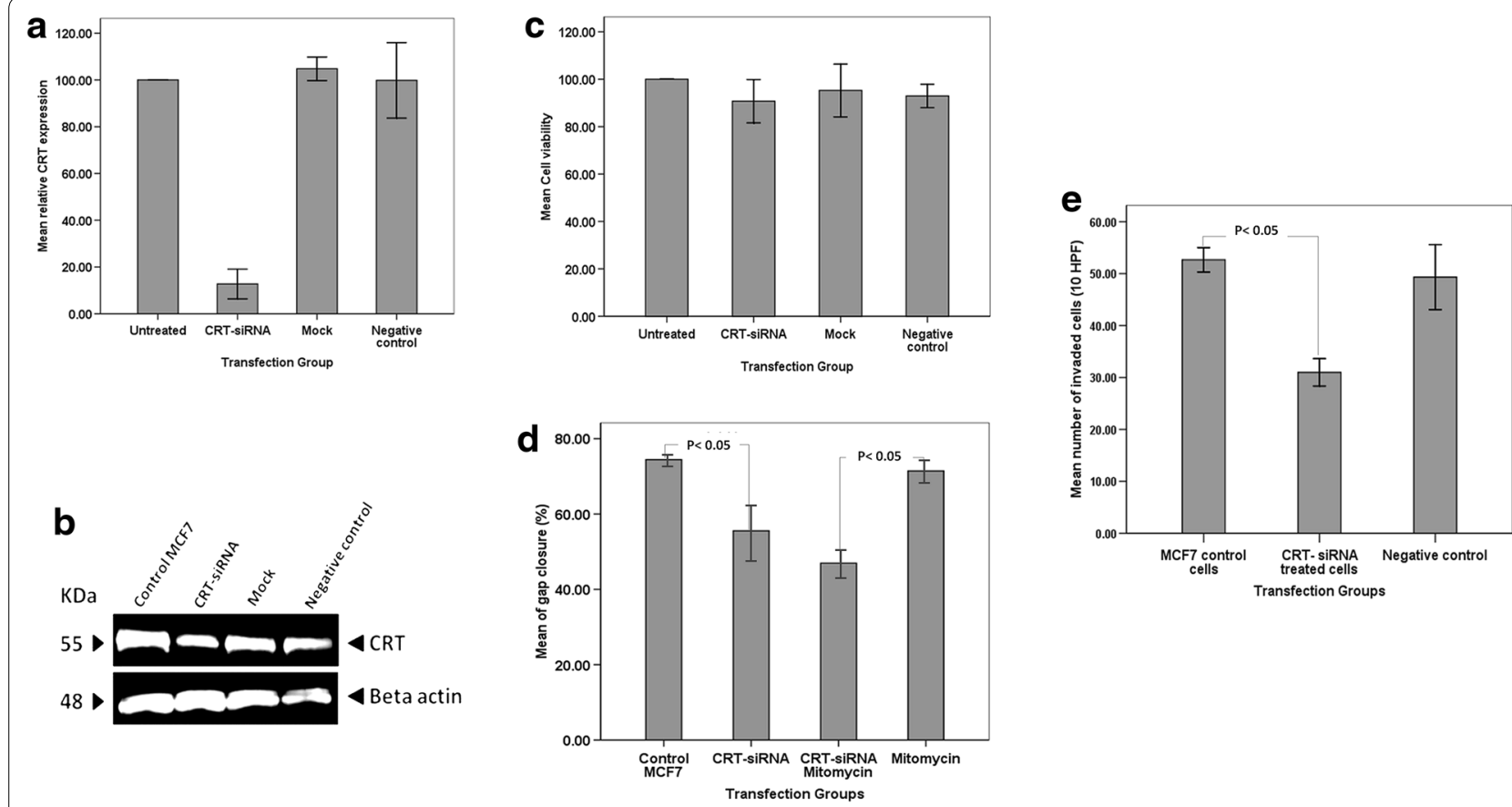

Transfection Groups

Fig. 3 The knockdown of CRT expression results in the inhibition of the migratory and invasive potential of MCF7 breast cancer cells. a Relative CRT expression analysis shows that more than $87 \%$ decrease in expression was achieved in CRT-knockdown cells. b Western blot results confirmed the down regulation of calreticulin expression in CRT-knockdown MCF7 cells as compared to control groups. Beta actin was used as the house-keeping control. c MTT assay showed $90.7 \%$ viability in CRT-siRNA transfected MCF7 cells as compared to the untreated group. d Migration assay results revealed a significant association between CRT expression and the migratory potential of MCF7 cells. The effect on migration was not proliferationdependent. e Statistical analysis of the invasion assay results showed a significant decrease in the number of invading cells following CRT-knockdown of MCF7 cells 


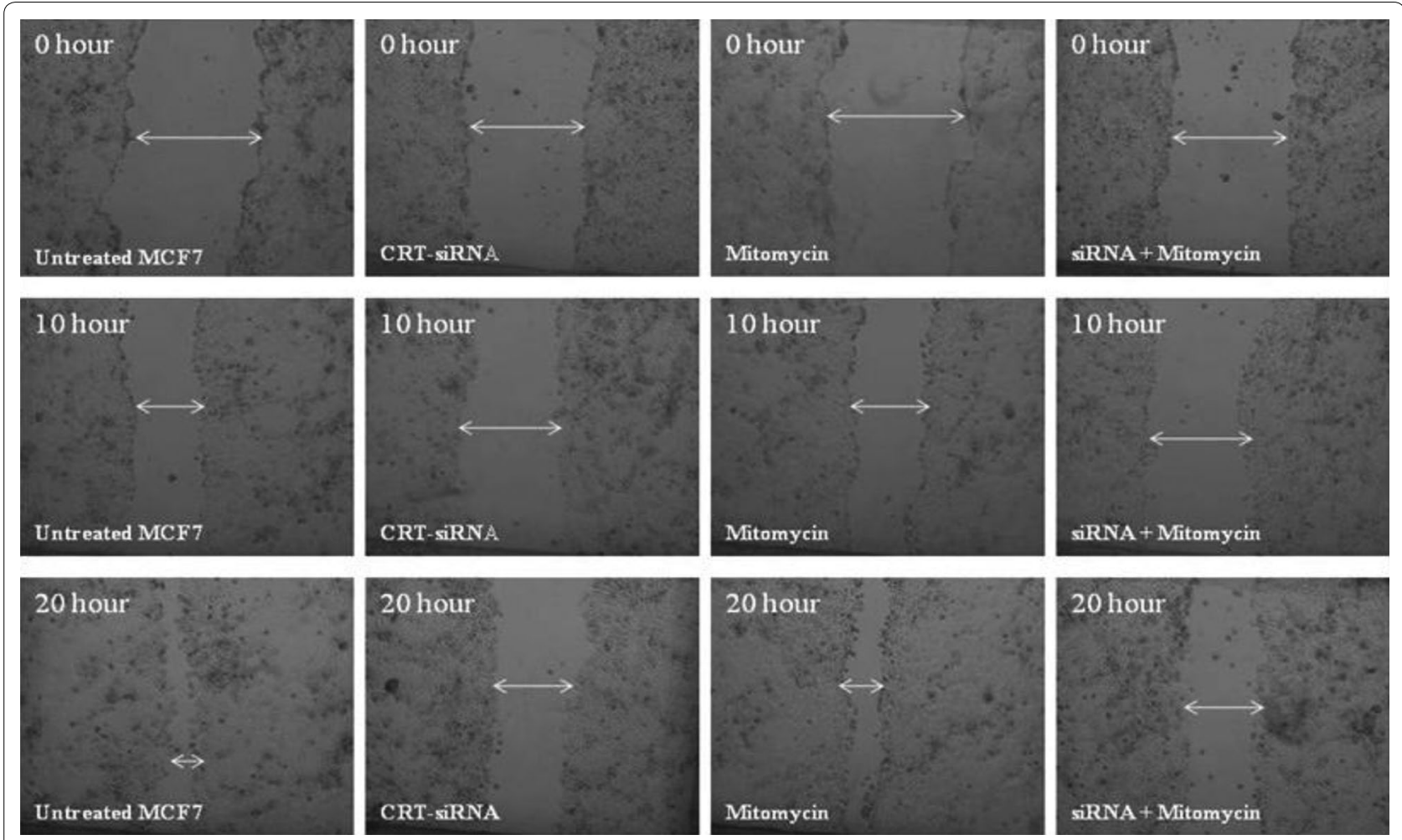

Fig. 4 Migration assay: comparing the speed in gap closure in a monolayer of cells. The images were captured at 0, 10 and $20 \mathrm{~h}$ post scratching. The CRT-siRNA knockdown cells displayed an obvious decrease in gap closure rate as compared to the control group in the absence and presence of mitomycin-C

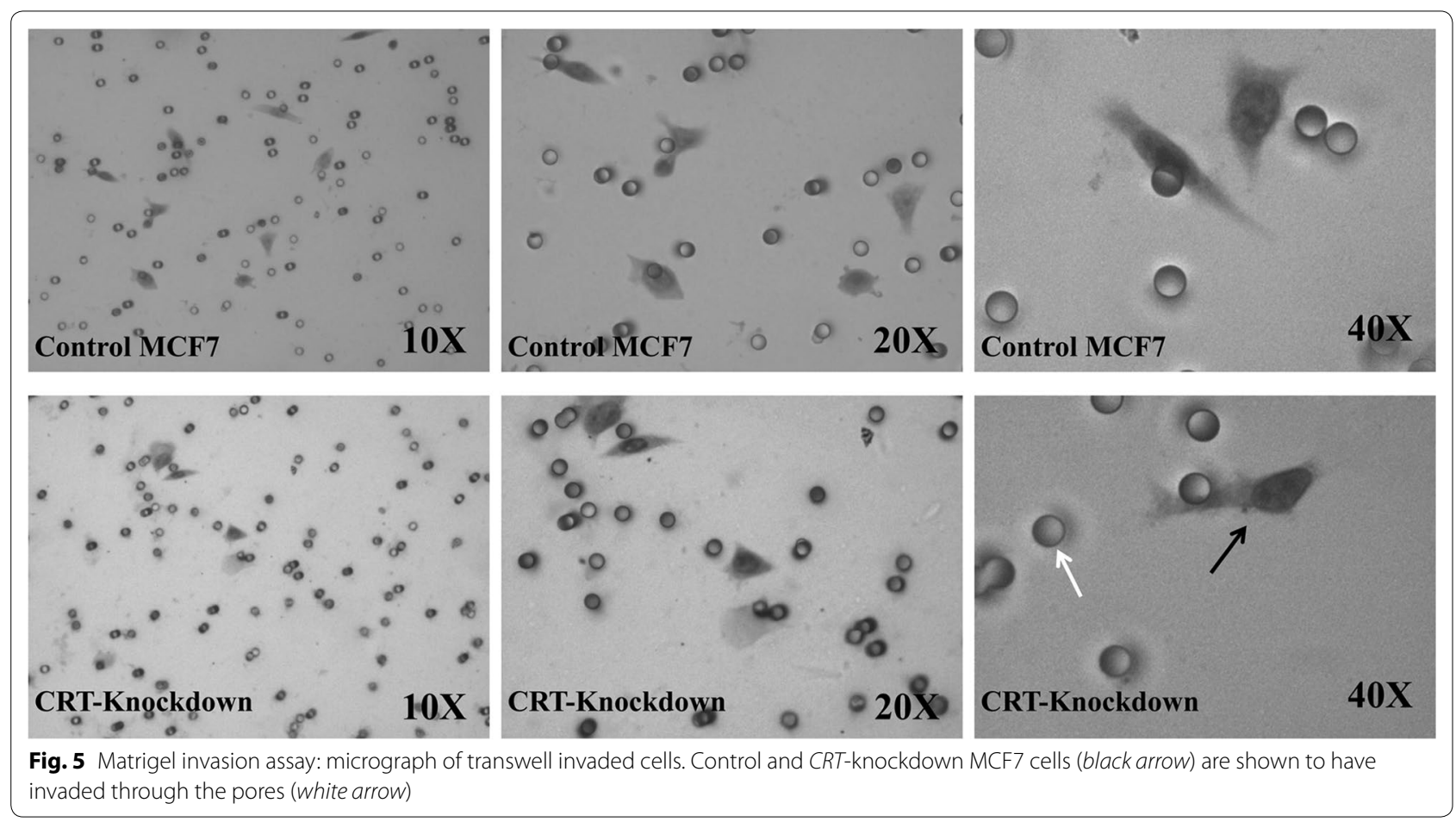


Table 2 The 10 most up/downregulated genes upon knockdown of $C R T$ expression

\begin{tabular}{llll}
\hline Gene name & Systematic name & Log FC & p value \\
\hline IFIT1 & NM_001548 & 2.9 & 0.00065 \\
IFIT2 & NM_001547 & 2.5 & $2.10 \mathrm{E}-05$ \\
IFI6 & NM_022873 & 2.3 & 0.00016 \\
IFIT3 & NM_001549 & 2.3 & 0.00033 \\
IFI27 & NM_005532 & 2.2 & 0.0034 \\
DDX58 & NM_014314 & 2 & $7.20 \mathrm{E}-06$ \\
DDX60 & NM_017631 & 2 & $5.00 \mathrm{E}-05$ \\
IFI27 & NM_005532 & 2 & 0.0045 \\
OASL & NM_003733 & 1.9 & $2.10 \mathrm{E}-05$ \\
SAMD9 & NM_017654 & 1.9 & $7.30 \mathrm{E}-05$ \\
CALR & NM_004343 & $\mathbf{- 2 . 7}$ & $\mathbf{5 . 2 0 E}-\mathbf{1 5}$ \\
MNT & AF318360 & -2.1 & $2.30 \mathrm{E}-13$ \\
CA306742 & CA306742 & -1.5 & $9.30 \mathrm{E}-12$ \\
FAM35A & NM_019054 & -0.67 & $4.90 \mathrm{E}-06$ \\
PCNXL3 & NM_032223 & -0.58 & $2.00 \mathrm{E}-07$ \\
C130rf37 & NM_001071775 & -0.57 & $2.70 \mathrm{E}-06$ \\
TACC2 & NM_206862 & -0.56 & 0.00025 \\
ENST00000301038 & ENST00000301038 & -0.5 & $5.40 \mathrm{E}-07$ \\
CPOX & NM_000097 & -0.46 & 0.00037 \\
TAOK3 & NM_016281 & -0.46 & 0.0023 \\
\hline GEnes & & &
\end{tabular}

Genes are listed based on their names, systematic names, fold changes in their expression (log $\mathrm{FC}$ ) and the $\mathrm{p}$ values. CRT as the most down-regulated gene is shown in bold

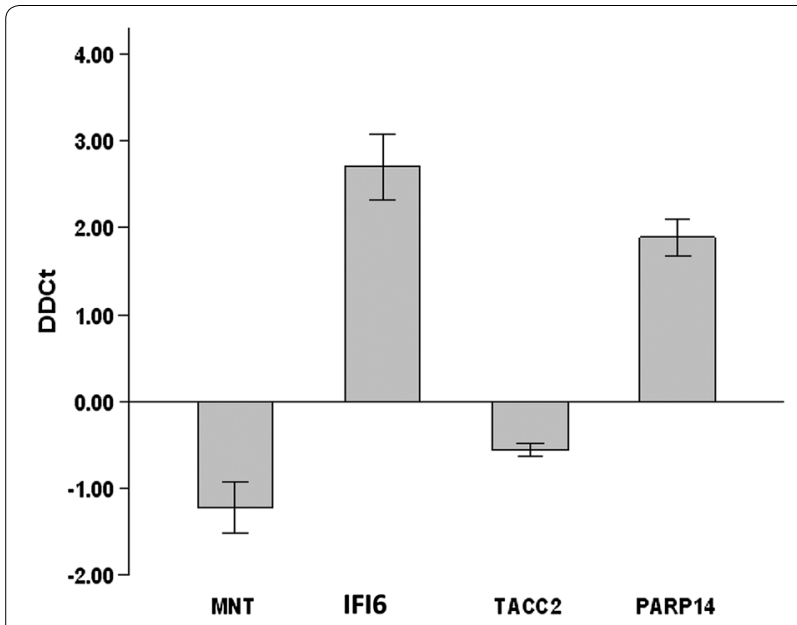

Fig. 6 Validation of microarray results by qPCR. The relative expression of selected genes are shown. IFI6 and PARP14 were upregulated in CRT-knockdown MCF7 cells while MNT and TACC2 were downregulated

\section{Discussion}

Our results demonstrate that the level of calreticulin expression in breast cancer is directly correlated with the invasiveness of the malignant lesions; represented by tumor stage/grade. This is in concordance with previous studies in which calreticulin overexpression was described in breast tumor epithelial cells, in which a correlation between calreticulin overexpression and the development of post-operative distant metastasis were reported [23, 24]. Calreticulin overexpression have also been reported in other malignant lesions such as esophageal squamous cell carcinoma [18], gastric cancer [19], pancreatic tumors [17], and even in melanoma cells [21].

The present study also reveals a significant upregulation of calreticulin in the stromal compartment of malignant tissues as compared to non-malignant tissues. To our knowledge, this is the first report that highlights the distinct calreticulin expression in the stroma of breast cancer. It is known that the growth and progression of malignant lesions entail the involvement of tumor stroma [25]. The stroma within the cancer microenvironment is usually subjected to different changes such as fibroblast activation, remodeling of extracellular matrix and finally angiogenesis [26]; where they are thought to act as a machinery for transforming the stroma into a protective microenvironment for metastasis [27]. Among the multiple inter players of the stroma/malignant cellular reaction, cancer-associated fibroblasts are drawing more attention as the receivers and creators of pro-tumorigenic signals [28]. In the present study, the characterization of calreticulin expression in breast cancer tissues shows the potential significance of its expression in the stroma.

The in vitro part of our study demonstrated that the migratory and invasive potential of $C R T$-knockdown MCF7 cells declined significantly as compared to the control groups. At the same time, MTT assay confirmed that these changes were not due to the alterations in the proliferative activity of the cells. These findings are in agreement with recent studies that indicate a role for calreticulin in conferring a pro-invasive and metastatic phenotype in a range of cancers, including breast adenocarcinoma [24, 29], gastric cancer [19], and esophageal squamous cell carcinoma [18].

Although the molecular mechanisms for cancer invasion and metastasis are not fully understood [30], different classes of proteins are involved or altered throughout this process. These proteins include cell adhesion molecules (CAMs) such as calcium dependent cadherin family, integrins and matrix proteases [31]. As calreticulin is also mainly involved in calcium homeostasis and protein chaperoning [5], several mechanisms can be proposed for its role in cancer initiation and progression. Calreticulin is able to prevent the anti-metastatic effects of estrogen receptor $\alpha(E R \alpha)$ in breast cancer [29], induce cell migration and wound healing [32], as well as affect apoptosis through the regulation of calcium stores of the cell [11, 
33, 34]. In addition, calreticulin effects on gene expression and cell adhesion are modulated indirectly through $\mathrm{Ca}^{2+}$ which makes it a central connector molecule inside a network of signaling pathways that are located in the endoplasmic reticulum [35]. On the cell surface, calreticulin regulates focal adhesion disassembly through the interaction with TSP/hep I complex suggesting it as an important component of the TSP signaling pathway that modulates cytoskeleton structure and supports the role in cell adhesion [36].

To propose a model of CRT gene interactions and related molecular pathways involved in conferring a more invasive breast cancer phenotype, further bioinformatic analysis was performed. Functional annotation of differentially expressed genes in CRT-knockdown cells revealed several dysregulated biological processes which can be suggested to be involved in calreticulin-associated pro-invasive effects. The most important dysregulated processes amongst the top gene ontologies were extracellular region, calcium homeostasis, DNA binding, regulation of transcription, estrogen metabolism and pathways, tumor progression, metastasis and cancer related processes. As expected, among the genes that were significantly up or downregulated, there were components of important signaling pathways such p53 and MAPK (Table 3) in which their possible interactions with calreticulin may contribute towards a more invasive breast cancer phenotype.

In the p53 pathway, active p53 functions as a transcription factor that upon sensing DNA damage or stress, will trigger a network of genes and their products such as TP53I11, TP53TG5 and SERPINB5 (maspin) that ultimately leads to cell cycle arrest, cellular senescence or apoptosis [37]. Our gene expression study confirmed that all these three p53 targets were significantly modulated following CRT knockdown in MCF7 cells (Fig. 7a). TP53I11 is a tumor suppressor gene that is involved in

Table 3 The fold-change in gene expression of p53 and MAPK related genes from the microarray-based whole genome expression analysis of CRT-knockdown of MCF7 cells

\begin{tabular}{lllll}
\hline Pathway & Gene name & Systematic name & Log FC & p value \\
\hline MAPK & MAP2K6 & NM_002758 & -0.37 & 0.00091 \\
& MAPK8 & ENST00000374189 & -0.16 & 0.031 \\
& MAP2K1 (MKK1) & NM_002755 & -0.12 & 0.31 \\
& MAP2K4 (MKK4) & NM_003010 & -0.11 & 0.18 \\
& MAPK1 (ERK2) & NM_138957 & -0.01 & 0.96 \\
p53 & MAPK14 (p38) & NM_001315 & -0.08 & 0.39 \\
& SERPINB5 & NM_002639 & 0.18 & 0.032 \\
& TP53/11 & NM_001076787 & 0.25 & 0.036 \\
& TP53TG5 & NM_014477 & 0.21 & 0.011
\end{tabular}

apoptosis [38]. TP53TG5 is a novel p53 target gene with cell cycle localization and growth suppressive effects in glioblastoma cells [39]. Finally, SERPINB5 (maspin) is a powerful tumor suppressor gene that is regulated by p53 at the transcriptional level and inhibits cell motility, invasion, angiogenesis and metastasis [40]. SERPINB5 is downregulated in breast cancer [41], and has the ability to modify the motility of breast cancer cells in vitro by inhibiting Rac1/Cdc42 activity [42]. In addition, SERPINB5 can potently inhibit the development of brain metastasis of breast cancer [43].

Our novel finding; significant upregulation $(\mathrm{p}<0.05)$ of the three p53 target genes following CRT-knockdown correlates with the inhibition of the migratory and invasive potential of breast cancer cells. Therefore, we postulate that calreticulin is possibly able to modify the inductive effects of activated p53 on its target genes. The mechanism behind calreticulin-blocking effect on p53 target genes is not clear. However, it can be related to the changes in $\mathrm{Ca}^{2+}$ homeostasis as p53 has been reported to interact with other $\mathrm{Ca}^{2+}$ binding molecules such as S100A2 [44].

The activation of MAPK signaling through the extracellular signal related kinase pathway (ERK1, 2) and or stress activated kinase pathway (JNK/p38 MAPK) will lead to sequential phosphorylation events (Fig. 7b), activation of transcription factors and finally gene expression regulation [45]. Erk1 and 2 are the most relevant MAPK components for breast cancer development [46], while the level of activated p38 expression is reported to be associated with the presence of lymph node metastasis in breast cancer [47].

Our results suggest that $C R T$ down-regulation in MCF7 cells will result in significant downregulation $(\mathrm{p}<0.05)$ of the expression levels of some of the components of MAPK pathway including MAP2K6 and MAPK8. In addition, some of the other MAPK components such as $M E K 1$ and MEK4 also showed reduction in their level of expression. These findings correspond to the significant decrease in the migratory and invasive potential of the cells. Therefore, calreticulin can be proposed to act as a potential inducer of the MAPK pathway. This can be supported by the fact that MAPK pathway activity is also modified by other $\mathrm{Ca}^{2+}$ homeostasis proteins such as Ras-GRF1, which is a $\mathrm{Ca}^{2+} /$ calmodulin-dependent Rasguanine-nucleotide-releasing factor [45], SERCA2 [48], and CaMKII (calcium/calmodulin-dependent protein kinase II gamma) [49].

\section{Conclusion}

This study shows that calreticulin expression in breast cancer is correlated with the degree of invasiveness; especially when stromal expression is considered. 


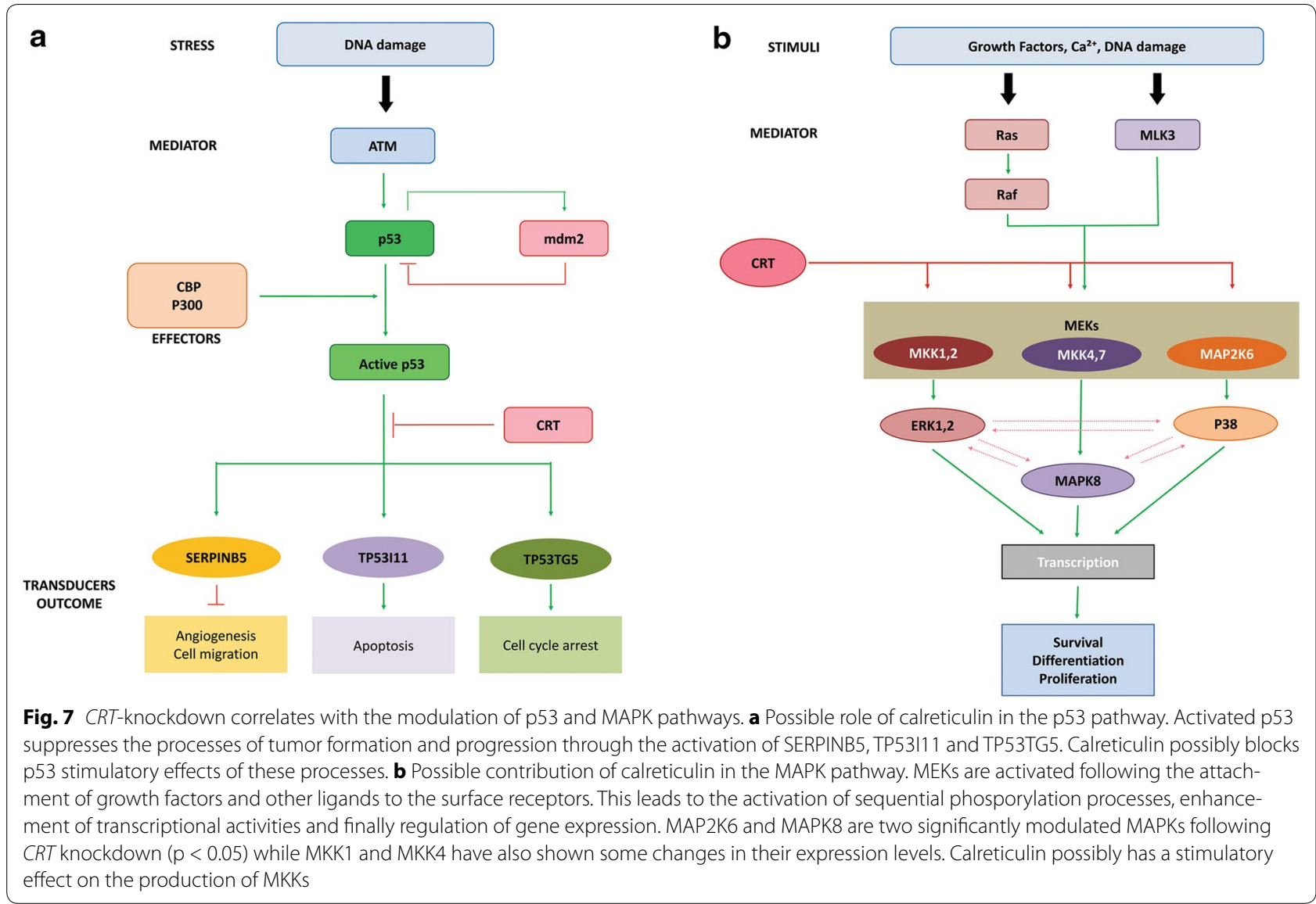

Furthermore, calreticulin confers a more invasive breast cancer phenotype. We conclude that calreticulin is able to promote breast cancer migration and invasion through the transcriptional modulation of important genes and associated pathways such as MAPK and p53 signaling. These downstream genes that have an active contribution towards the malignant transformation of cancer cells are possibly the actual targets of calreticulin-associated proinvasive effects and will need to be further evaluated in future studies.

\section{Methods}

\section{Human breast tissue samples and breast cancer cell line}

Fresh frozen breast cancer tissues for this study were obtained from Hospital Universiti Kebangsaan Malaysia. Ethics approval and patient informed consent including consent to participate in the study and consent to publish was obtained in written in accordance to the Universiti Kebangsaan Malaysia Research and Medical Ethics Committee (Approval No. FF-166-2004). Fresh frozen samples of infiltrating ductal carcinoma and adjacent normal tissues were collected from 12 patients who underwent breast surgery. The samples were snap frozen and stored at $-80{ }^{\circ} \mathrm{C}$ until protein analysis was performed. Formalin-fixed paraffin-embedded (FFPE) samples were obtained from the Pathology Department of Milad Hospital, Tehran, Iran, courtesy of Dr. Saadat Molanaii. These included 10 non-malignant and 38 malignant samples. Non-malignant samples were mainly from fibrocystic changes of the breast while all of the malignant tissues were diagnosed as ductal carcinoma. Malignant samples were stratified based on the grade as well as the stage of the tumors. MCF7 cell line was purchased from the American Type Culture Collection (ATCC) and used for the in vitro part of this study,

\section{Two-Dimensional Gel Electrophoresis}

For the first dimension, $17 \mathrm{~cm} \mathrm{pH} \mathrm{4-7} \mathrm{L} \mathrm{IPG} \mathrm{strips} \mathrm{(Bio-}$ Rad, Hercules, CA, USA) were used. The samples were passively rehydrated overnight using a rehydration buffer containing $7 \mathrm{M}$ urea (Bio-Rad), $2 \mathrm{M}$ thiourea (GE healthcare, Uppsala, Sweden), $2 \%$ CHAPS (GE Healthcare), $1 \%$ IPG buffer (pH 4-7) (GE healthcare), $0.2 \%$ DTT (BioRad) and bromophenol blue (Bio-Rad). The rehydrated 
IPG strips were focused using PROTEAN IEF cell (BioRad). The current was applied in 3 steps; $250 \mathrm{~V}$ was applied in linear ramp for $20 \mathrm{~min}$, then $10,000 \mathrm{~V}$ for $2.5 \mathrm{~h}$ in linear ramp and finally, the current increased rapidly to $40,000 \mathrm{~V} / \mathrm{hr}$ when the isoelectric focusing was achieved. The strips were stored at $-80{ }^{\circ} \mathrm{C}$ until the second dimension gel electrophoresis was performed. Strips were then equilibrated in two steps for 15 min each using an equilibration buffer consisting of $0.1 \mathrm{M}$ Tris $\mathrm{HCl}$ (Amresco, Solon, OH, USA) pH 8.8, $6 \mathrm{M}$ urea (Bio-Rad) 30 \% Glycerol (GE Healthcare), $4 \%$ SDS (GE Healthcare), $0.002 \%$ Bromophenol Blue (Bio-Rad). In the first step of equilibration, $26 \mathrm{mM}$ DDT (Bio-Rad) was added to the buffer, while $0.38 \mathrm{M}$ of Iodoacetamide (Bio-Rad) was added to the buffer in the next step. The second dimension was then performed on $10 \%$ SDS-polyacrylamide gels.

\section{Gel staining and analysis}

The gels were stained with silver staining and scanned using the GS-800 Calibrated Densitometer (Bio-Rad). The PDQuest software 7.3 (Bio-Rad) was used for differential analysis of the gels. The spots with at least a twofold increase were picked manually and stored at $4{ }^{\circ} \mathrm{C}$ until in-gel digestion was carried out.

\section{Protein identification by MALDI-TOF MS}

The excised spots were destained by first washing with a digestion buffer ( $25 \mathrm{mM}$ ammonium bicarbonate) and then with $50 \%$ acetonitrile digestion buffer. These steps were repeated three times. Digestion was performed with sequencing grade trypsin (Promega, Madison, WI, USA) at $37{ }^{\circ} \mathrm{C}$ overnight. The resulting tryptic peptides were extracted from the gels, then desalted and concentrated with C18 ziptip (Millipore, Billerica, MA, USA) before spotting for matrix-assisted laser desorption ionizationtime-of-flight (MALDI-TOF) analysis.

\section{Immunohistochemistry}

Immunohistochemistry was performed to evaluate histological expression of calreticulin using a mouse monoclonal [FMC 75] antibody (Abcam, Cambridge, UK) through the following protocol: $0.4 \mu$ tissue sections were mounted on polysine-coated slides (Menzel, Berlin, Germany). After dewaxation and dehydration, heat induced antigen retrieval was done using Tris-EDTA buffer $(\mathrm{pH}$ : 9.0) for $10 \mathrm{~min}$ in sub-boiling conditions. This was followed by internal peroxidase inhibition with $3 \% \mathrm{H} 2 \mathrm{O} 2$ for 10 min, blocking with $5 \%$ BSA for $2 \mathrm{~h}$, and then treatment with a primary antibody (anti-calreticulin) for $45 \mathrm{~min}$ at a concentration of $0.15 \mu \mathrm{gr} / \mathrm{mL}$. For detection, Real $^{\mathrm{TM}}$ EnVision $^{\mathrm{TM}}$ Detection System (Dako, Glostrup, Denmark) was used for $30 \mathrm{~min}$ followed by chromogen staining using diaminobenzidine (DAB) for $10 \mathrm{~min}$ and finally counterstained by hematoxylin. All the procedures were carried out at room temperature.

\section{Scoring the $\mathrm{IHC}$ results}

An independent committee blinded to pathologic details of the specimens was assigned to score the IHC results. Three different histological areas of each malignant tissue including glandular, invasive and stromal parts were examined. These scores were calculated based on the intensity of the brown staining (1-3 plus) as well as the proportion of stained cells in glandular epithelium $(<50 \%=0,70-50 \%=1,90-70 \%=2$ and $>90 \%=3)$ as well as stroma $(<10 \%=1,10-50 \%=2$ and $>50 \%=3)$.

\section{RNA isolation \& CDNA synthesis}

Total RNA extraction was performed using RNeasy mini kit (Qiagen, Valencia, CA, USA) following the manufacturer's protocol. The concentration and quality of RNA were examined by measuring the absorbance ratios at $260 \mathrm{~nm}$ and $280 \mathrm{~nm}$ using the NanoDrop $2000 \mathrm{spec}-$ trophotometer (Thermoscientific, West Palm Beach, FL, USA) and running the samples on $1 \%$ agarose gel, respectively. Finally, the RNA samples were reverse transcribed into cDNA using the Revert $\mathrm{Aid}^{\mathrm{TM}} \mathrm{H}$ minus First Strand cDNA Synthesis kit (Thermoscientific) according to the manufacturer's instructions.

\section{Real-time PCR}

The expression level for $C R T$ as the gene of interest and beta actin as the housekeeping (reference) gene were examined using the SensiMixPlus SYBR kit (Quantace, London, UK) and then quantified based on the standard curve method. The primers were designed in a manner to amplify only the cDNAs compatible to the mRNA sequence but not the genomic sequence. The sequences of the primers for $C R T$ are as follows: GGCGGCACCACCATGTACCCT (forward) and AGGGGCCGGACTCGTCATACT (reverse) while that for beta-actin are CTTCAAGGAGCAGTTTCTGG (forward) and GCTTGTCTGCAAACCTTTATC (reverse). The protocol for PCR was as follows: initial denaturation at $95^{\circ} \mathrm{C}$ for $10 \mathrm{~min}$, denaturation at $95^{\circ} \mathrm{C}$ for $30 \mathrm{~s}$, annealing at $52^{\circ} \mathrm{C}$ $\left(59^{\circ} \mathrm{C}\right.$ for beta actin) for $30 \mathrm{~s}$, elongation at $72^{\circ} \mathrm{C}$ for $45 \mathrm{~s}$, and final elongation at $72{ }^{\circ} \mathrm{C}$ for $10 \mathrm{~min}$. The reaction was run for 35 cycles.

\section{Protein isolation}

MCF7 cells were cultured until they reached 70-90\% confluence and were then lysed with a solution of $40 \mathrm{mM}$ Tris (GE Healthcare, WI, USA), $7 \mathrm{M}$ urea (Invitrogen, Carlsbad, CA, USA), $2 \mathrm{M}$ thiourea (Invitrogen), $4 \%$ CHAPS (Invitrogen), $65 \mathrm{mM}$ Dithiothreitol (Invitrogen), $1 \mathrm{mM}$ EDTA (Amresco) and $10 \mu \mathrm{l}$ of Halt Protease Inhibitor Cocktail (Thermoscientific). 


\section{Western blot}

The isolated proteins were run on $12.5 \%$ polyacrylamide resolving gel and then transferred to a PVDF membrane and treated with the primary antibody at $4{ }^{\circ} \mathrm{C}$ overnight either using 1:200 dilution of mouse monoclonal antibody against human calreticulin 1G6A7 (Santa Cruz Biotechnology, Santa Cruz, CA, USA) or 1:10,000 dilution of mouse monoclonal [Ac-15] antibody against human beta actin (Genetex, Irvine, CA, USA). This was followed by an incubation in 1:2500 dilution of the secondary antibody (ImmunoPure Goat Anti-Mouse IgG, $(\mathrm{H}+\mathrm{L})$, Peroxidase Conjugated, Thermoscientific). The detection was carried out by a chemiluminescence method using SuperSignal West Pico Chemiluminescent Substrate (Thermoscientific).

\section{siRNA gene knockdown}

For CRT knockdown, ON-TARGETplus SMARTpool (Thermoscientific) and DharmaFECT 1 as the transfection reagent were used. Three controls were included in the experiment including untreated, negative and mock controls. For negative control (NC), ON-TARGETplus SMARTpool was replaced by non-targeting pool of siRNA. In mock control (M), ON-TARGETplus SMARTpool was replaced by equal amounts of antibiotic- and serum-free media. Finally, ON-TARGETplus SMARTpool and DharmaFECT 1 were replaced by antibiotic- and serum-free media in the untreated control (UT). For mRNA analysis, cells were harvested $36 \mathrm{~h}$ posttransfection while protein extraction was carried out at $72 \mathrm{~h}$ post-transfection.

\section{MTT assay}

MCF7 cells were cultured on 96-well plates in triplicates containing CRT-siRNA transfected or related control groups. At $24 \mathrm{~h}$ post-transfection, $20 \mu \mathrm{l}$ of $5 \mathrm{mg} / \mathrm{ml} \mathrm{MTT}$ solution was added to each well and incubated for $3.5 \mathrm{~h}$ at $37{ }^{\circ} \mathrm{C}$ and $5 \% \mathrm{CO}_{2}$. The content of each well was then replaced with $100 \mu \mathrm{l}$ of DMSO (dimethyl sulfoxide). The plate was covered with an aluminium foil and agitated in an orbital shaker at room temperature for $15 \mathrm{~min}$. Finally, the absorbance was read at $590 \mathrm{~nm}$ with a reference filter at $620 \mathrm{~nm}$ using an ELISA reader.

\section{Migration assay}

Four triplicates of MCF7 cells were grown on 12-well plates and incubated at $37{ }^{\circ} \mathrm{C}$ and $5 \% \mathrm{CO}_{2}$ until the cultures reached $70 \%$ confluency. Two sets of cells were transfected with $C R T$-siRNA and the cultures were kept at $37{ }^{\circ} \mathrm{C}$ and $5 \% \mathrm{CO}_{2}$ for another $72 \mathrm{~h}$. Then, $10 \mu \mathrm{g} / \mathrm{ml}$ mitomycin C (Merck, Whitehouse Station, NJ, USA) was added to one set of each triplicate (both siRNA treated and untreated). After $2 \mathrm{~h}$, a longitudinal scratch was made on the central line of each well alongside the pre-applied marks at the bottom of each plate. Using a microscope with an attached camera (Leica, Wetzlar, Germany), images were captured from the specified marked loci of the gaps that were produced by the scratch on the monolayer of cells. Image capturing was repeated at certain time points including $0,3,6,10,15,20,24,28,32$ and $36 \mathrm{~h}$ post-scratching. Finally, the diameter of the gap was measured in three different loci of each replicate at the specified marked areas using the Nis-Elements imaging software version 3.00 SP7. The average readings were calculated and the proportion of differences in the gap diameter at 0 and $20 \mathrm{~h}$ were used to compare the migratory potential of the different groups.

\section{Invasion assay}

At $48 \mathrm{~h}$ post-transfection, the media was replaced by serum-free DMEM overnight to simulate starving conditions. The following day, cells were harvested and diluted at a concentration of $1 \times 10^{5}$ cells $/ \mathrm{mL}$. The lower compartment of BD companion plates (BD, Franklin Lakes, NJ, USA) were filled with $750 \mu \mathrm{l}$ of DMEM including $10 \%$ FBS. Then, matrigel-coated inserts were placed inside the wells and $500 \mu \mathrm{l}$ of cell suspension $\left(5 \times 10^{4}\right.$ cells $)$ was added into each well and incubated at $37{ }^{\circ} \mathrm{C}$ and $5 \% \mathrm{CO}_{2}$ for $24 \mathrm{~h}$. The inserts were then incubated in $100 \%$ methanol for $10 \mathrm{~min}$, washed in PBS twice and stained in hematoxylin for 2-5 min. Finally, the filter membranes were cut and mounted on slides using DPX (Merck). The total number of invaded cells in 10 random HPF was counted at $10 \times$ magnification of a light microscope.

\section{Genome wide expression analysis}

A triplicate hybridization of CRT-siRNA transfected MCF7 cells versus mock control was prepared and total RNA was extracted $36 \mathrm{~h}$ post-transfection. Only RNA samples with high quality (A260/A280 and A260/230 were set at $\geq 1.8$ and $\geq 1.5$, respectively) were picked for further evaluation. Agilent Whole Human Genome Microarray $4 \times 44 \mathrm{~K}$ G4112F (Agilent, Palo Alto, CA, USA) which, consisted of 43,376 oligonucleotides was used for expression profiling. The preparation of expression arrays, hybridization process and scan readings were carried out by Oxford Gene Technology (Oxfordshire, UK). The microarray data was deposited in NCBI's Gene Expression Omnibus [50] and is accessible through GEO Series accession number GSE44371.

\section{Statistical analysis}

For the IHC results, one-way ANOVA followed by post hoc test (Duncan option) was used. In other experiments, independent Student's t test was used to determine any statistical significance of the results. 


\section{Additional files}

Additional file 1: Table S1. Protein identification of the excised spots.

Additional file 2: Table S2. Relative quantification of CRT expression in MCF7 cells.

Additional file 3: Table S3. Migration assay results.

Additional file 4: Table S4. Invasion assay results.

Additional file 5: Table S5. The most important gene ontologies related to a subset of significant dysregulated genes.

\section{Abbreviations}

CRT: calreticulin; 2D: two dimensional; MALDI-TOF: matrix-assisted laser desorption/ionization time of flight; FFPE: formalin-fixed paraffin-embedded; ER: endoplasmic reticulum; siRNA: small interfering RNA; HPF: high power field; qPCR: quantitative polymerase chain reaction; IDC: intra ductal carcinoma; IHC: immunohistochemistry; nm: nanometer.

\section{Authors' contributions}

MZ carried out the IHC analysis, CRT-knockdown experiments and bioinformatics analysis as well as drafted the manuscript. LAQH carried out the $2 \mathrm{D}$ gel electrophoresis and MALDI-TOF. RR participated in the design of the study, editing and final verifications. AV conceived the study and was involved in the drafting and editing of the manuscript. SAR helped in the pathological assessment and scoring of the tissue samples. SS assisted in the statistical analysis of the IHC results. All authors read and approved the final manuscript.

\section{Author details}

${ }^{1}$ Department of Genetics, Reproductive Biomedicine Research Center, Royan Institute for Reproductive Biomedicine, ACECR, Tehran, Iran. ${ }^{2}$ Medical Genetics Laboratory, Faculty of Medicine and Health Sciences, Universiti Putra Malaysia, 43400 Serdang, Selangor Darul Ehsan, Malaysia. ${ }^{3}$ Department of Pharmacy, Faculty of Pharmacy, Al-Zaytoonah University of Jordan, Amman 11733, Jordan. ${ }^{4}$ Perdana University Graduate School of Medicine, Perdana University, 43400 Serdang, Selangor Darul Ehsan, Malaysia. ${ }^{5}$ Cluster of Medical Laboratory Sciences, Faculty of Medicine, Universiti Teknologi MARA, Selayang Campus, 68100 Batu Caves, Selangor, Malaysia. ${ }^{6}$ Department of Biology, Faculty of Science, Universiti Putra Malaysia, 43400 Serdang, Selangor, Malaysia.

${ }^{7}$ UPM-MAKNA Cancer Research Laboratory, Institute of Bioscience, Universiti Putra Malaysia, 43400 Serdang, Selangor, Malaysia.

\section{Acknowledgements}

This work was supported by funding from the Research University Grant Scheme, Universiti Putra Malaysia (UPM), Grant No. 04/01/07/0110RU and a Graduate Research Fellowship from UPM that was awarded to Mohammadreza Zamanian. The authors wish to thank Professor Sharifah Noor Akmal for providing the clinical specimens used in the study.

\section{Competing interests}

The authors declare that they have no competing interests.

Received: 10 May 2014 Accepted: 31 May 2016

Published online: 13 July 2016

\section{References}

1. Berns EMJJ. Use of micro array analysis to predict out come and response in breast cancer patients. Br J Cancer Suppl. 2004;9:49-50.

2. Jemal A, Siegel R, Ward E, Hao Y, Xu J, Thun MJ. Cancer statistics, 2009. CA Cancer J Clin. 2009:59:225-49.

3. Green M, Raina V. Epidemiology, screening and diagnosis of breast cancer in the Asia-Pacific region: current perspectives and important considerations. Asia-Pacific J Clin Oncol. 2008;4:S5-13.

4. van de Vijver M. Gene-expression profiling and the future of adjuvant therapy. Oncologist. 2005;10:30-4.
5. Michalak M, Corbett EF, Mesaeli N, Nakamura K, Opas M. Calreticulin: one protein, one gene, many functions. Biochem J. 1999;344:281-92.

6. Nakamura K, Zuppini A, Arnaudeau S, Lynch J, Ahsan I, Krause R, Papp S, De Smedt H, Parys JB, Müller-Esterl W, et al. Functional specialization of calreticulin domains. J Cell Biol. 2001;154:961-72.

7. Orr AW, Elzie CA, Kucik DF, Murphy-Ullrich JE. Thrombospondin signaling through the calreticulin/LDL receptor-related protein co-complex stimulates random and directed cell migration. J Cell Sci. 2003;116:2917-27.

8. Opas M, Dziak E, Fliegel L, Michalak M. Regulation of expression and intracellular distribution of calreticulin, a major calcium binding protein of nonmuscle cells. J Cell Physiol. 1991;149:160-71.

9. Gao B, Adhikari R, Howarth M, Nakamura K, Gold MC, Hill AB, Knee R, Michalak M, Elliott T. Assembly and antigen-presenting function of MHC class I molecules in cells lacking the ER chaperone calreticulin. Immunity. 2002;16:99-109.

10. Yoon G-S, Lee H, Jung Y, Yu E, Moon H-B, Song K, Lee I. Nuclear matrix of calreticulin in hepatocellular carcinoma. Cancer Res. 2000;60:1117-20.

11. Chen D, Texada DE, Duggan C, Liang C, Reden TB, Kooragayala LM, Langford MP. Surface calreticulin mediates muramyl dipeptide-induced apoptosis in RK13 cells. J Biol Chem. 2005;280:22425-36.

12. Zamanian M, Veerakumarasivam A, Rosli R, Abdullah S. Calreticulin and cancer. Pathol Oncol Res. 2013;19:149.

13. Bini L, Magi B, Marzocchi B, Arcuri F, Tripodi S, Cintorino M, Sanchez J-C, Frutiger S, Hughes G, Pallini V, et al. Protein expression profiles in human breast ductal carcinoma and histologically normal tissue. Electrophoresis. 1997;18:2832-41.

14. Kageyama S, Isono T, Iwaki H, Wakabayashi Y, Okada Y, Kontani K, Yoshimura K, Terai A, Arai Y, Yoshiki T. Identification by proteomic analysis of calreticulin as a marker for bladder cancer and evaluation of the diagnostic accuracy of its detection in urine. Clin Chem. 2004;50:857-66.

15. Ayodele A, Uwe R, Lars E, Adelaide C, Bo F, Daniela V, Sören H, Stig L, Gert A. Polypeptide expression in prostate hyperplasia and prostate adenocarcinoma. Anal Cell Pathol. 2000;21:1-9.

16. Kim Y, Kim H-J, Song E, Lee K-J. Glucoronic acid is a novel inducer of heat shock response. Mol Cell Biochem. 2004;259:23-33.

17. Hong S-H, Misek DE, Wang H, Puravs E, Giordano TJ, Greenson JK, Brenner DE, Simeone DM, Logsdon CD, Hanash SM. An autoantibody-mediated immune response to calreticulin isoforms in pancreatic cancer. Cancer Res. 2004;64:5504-10.

18. Du XL, Yang H, Liu SG, Luo ML, Hao JJ, Zhang Y, Lin DC, Xu X, Cai Y, Zhan QM, Wang MR. Calreticulin promotes cell motility and enhances resistance to anoikis through STAT3-CTTN-Akt pathway in esophageal squamous cell carcinoma. Oncogene. 2009;28:3714-22.

19. Chen CN, Chang CC, Su TE, Hsu WM, Jeng YM, Ho MC, Hsieh FJ, Lee PH, Kuo ML, Lee H, Chang KJ. Identification of calreticulin as a prognosis marker and angiogenic regulator in human gastric cancer. Ann Surg Oncol. 2009;16:524-33

20. Vougas K, Gaitanarou E, Marinos E, Kittas C, Voloudakis-Baltatzis IE. Two-dimensional electrophoresis and immunohistochemical study of calreticulin in colorectal adenocarcinoma and mirror biopsies. J BUON. 2008:13:101-7.

21. Dissemond J, Busch M, Kothen T, Mörs J, Weimann TK, Lindeke A, Goos M, Wagner SN. Differential downregulation of endoplasmic reticulum-residing chaperones calnexin and calreticulin in human metastatic melanoma. Cancer Lett. 2004:203:225-31.

22. Helbling D, Mueller BU, Timchenko NA, Schardt J, Eyer M, Betts DR, Jotterand M, Meyer-Monard S, Fey MF, Pabst T. CBFB-SMMHC is correlated with increased calreticulin expression and suppresses the granulocytic differentiation factor CEBPA in AML with inv(16). Blood. 2005;106:1369-75.

23. Eric A, Juranic Z, Milovanovic Z, Markovic I, Inic M, Stanojevic-Bakic N, Vojinovic-Golubovic V. Effects of humoral immunity and calreticulin overexpression on postoperative course in breast cancer. Pathol Oncol Res. 2009;15:89-90.

24. Lwin Z-M, Guo C, Salim A, Yip GW-C, Chew F-T, Nan J, Thike AA, Tan P-H, Bay B-H. Clinicopathological significance of calreticulin in breast invasive ductal carcinoma. Mod Pathol. 2010:23:1559.

25. Kalluri R, Zeisberg M. Fibroblasts in cancer. Nat Rev Cancer. 2006:6:392-401.

26. Tuxhorn JA, MCAlhany SJ, Dang TD, Ayala GE, Rowley DR. Stromal cells promote angiogenesis and growth of human prostate tumors 
in a differential reactive stroma (DRS) xenograft model. Cancer Res. 2002;62:3298-307.

27. Mueller MM, Fusenig NE. Friends or foes_-bipolar effects of the tumour stroma in cancer. Nat Rev Cancer. 2004;4:839-49.

28. Östman A, Augsten M. Cancer-associated fibroblasts and tumor growth - bystanders turning into key players. Curr Opin Genet Dev. 2009;19:67-73.

29. Platet N, Cunat S, Chalbos D, Rochefort H, Garcia M. Unliganded and liganded estrogen receptors protect against cancer invasion via different mechanisms. Mol Endocrinol. 2000;14:999-1009.

30. Janda E, Lehmann K, Killisch I, Jechlinger M, Herzig M, Downward J, Beug $H$, Grünert S. Ras and TGF $\beta$ cooperatively regulate epithelial cell plasticity and metastasis. J Cell Biol. 2002;156:299-314.

31. Hanahan D, Weinberg RA. The hallmarks of cancer. Cell. 2000;100:57-70.

32. Gold LI, Rahman M, Blechman KM, Greives MR, Churgin S, Michaels J, Callaghan MJ, Cardwell NL, Pollins AC, Michalak M, et al. Overview of the role for calreticulin in the enhancement of wound healing through multiple biological effects. J Investig Dermatol Symp Proc. 2006;1 1:57-65.

33. Mesaeli N, Phillipson C. Impaired p53 expression, function and nuclear localization in calreticulin deficient cells. Mol Biol Cell. 2004;15:1862.

34. Vanoverberghe $K$, Vanden Abeele F, Mariot P, Lepage G, Roudbaraki M, Bonnal JL, Mauroy B, Shuba Y, Skryma R, Prevarskaya N. Ca ${ }^{2+}$ homeostasis and apoptotic resistance of neuroendocrine-differentiated prostate cancer cells. Cell Death Differ. 2003;11:321-30.

35. Michalak M, Robert Parker JM, Opas M. $\mathrm{Ca}^{2+}$ signaling and calcium binding chaperones of the endoplasmic reticulum. Cell Calcium. 2002;32:269-78.

36. Goicoechea S, Pallero MA, Eggleton P, Michalak M, Murphy-Ullrich JE. The anti-adhesive activity of thrombospondin is mediated by the $\mathrm{N}$-terminal domain of cell surface calreticulin. J Biol Chem. 2002;277:37219-28.

37. Harris SL, Levine AJ. The p53 pathway: positive and negative feedback loops. Oncogene. 2005;24:2899-908.

38. Wu Y, Liu X-M, Wang X-J, Zhang Y, Liang X-Q, Cao E-H. PIG1 1 is involved in hepatocellular carcinogenesis and its over-expression promotes Hepg2 cell apoptosis. Pathol Oncol Res. 2009;15:411-6.

39. Isaka S, Takei Y, Tokino T, Koyama K, Miyoshi Y, Suzuki M, Takahashi E, Azuma C, Murata Y, Nakamura Y. Isolation and characterization of a novel TP53-inducible gene, TP53TG5, which suppresses growth and shows cell cycle-dependent transition of expression. Genes Chromosomes Cancer. 2000;27:345-52.

40. Hendrix MJC. De-mystifying the mechanism(s) of maspin. Nat Med. 2000;6:374-6.

41. Zou Z, Anisowicz A, Hendrix M, Thor A, Neveu M, Sheng S, Rafidi K, Seftor E, Sager R. Maspin, a serpin with tumor-suppressing activity in human mammary epithelial cells. Science. 1994;263:526-9.

42. Shi HY, Stafford LJ, Liu Z, Liu M, Zhang M. Maspin controls mammary tumor cell migration through inhibiting Rac1 and Cdc42, but not the RhoA GTPase. Cell Motil Cytoskeleton. 2007;64:338-46.

43. Stark A, Schem C, Maass N, Hugo HH, Jonat W, Mehdorn HM, Held-Feindt J. Expression of metastasis suppressor gene maspin is reduced in breast cancer brain metastases and correlates with the estrogen receptor status. Neurol Res. 2010;32:303-8.

44. Mueller A, Schäfer BW, Ferrari S, Weibel M, Makek M, Höchli M, Heizmann CW. The calcium-binding protein S100A2 interacts with p53 and modulates its transcriptional activity. J Biol Chem. 2005;280:29186-93.

45. Thomas GM, Huganir RL. MAPK cascade signalling and synaptic plasticity. Nat Rev Neurosci. 2004;5:173-83.

46. Santen RJ, Song RX, McPherson R, Kumar R, Adam L, Jeng M-H, Yue W. The role of mitogen-activated protein (MAP) kinase in breast cancer. J Steroid Biochem Mol Biol. 2002:80:239-56.

47. Han Y, Liu L, Yan D, Wang G. Correlation between expression of P38 MAPK-signaling and UPA in breast cancer. Chin J Clin Oncol. 2008:5:161-4.

48. Andrews C, Ho PD, Dillmann WH, Glembotski CC, McDonough PM. The MKK6 - p38 MAPK pathway prolongs the cardiac contractile calcium transient, downregulates SERCA2, and activates NF-AT. Cardiovasc Res. 2003:59:46-56.

49. Kandilci A, Grosveld GC. SET-induced calcium signaling and MAPK/ERK pathway activation mediate dendritic cell-like differentiation of U937 cells. Leukemia. 2005;19:1439-45.

50. Edgar R, Domrachev M, Lash AE. Gene expression omnibus: NCBI gene expression and hybridization array data repository. Nucleic Acids Res. 2002;30:207-10.

\section{Submit your next manuscript to BioMed Central and we will help you at every step:}

- We accept pre-submission inquiries

- Our selector tool helps you to find the most relevant journal

- We provide round the clock customer support

- Convenient online submission

- Thorough peer review

- Inclusion in PubMed and all major indexing services

- Maximum visibility for your research

Submit your manuscript at www.biomedcentral.com/submit
() Biomed Central 